\title{
Проблема ортопедического лечения больных с концевыми дефектами зубного ряда
}

\author{
С.В. Микляев, О.М. Леонова, А.Н. Сальников, А.В. Новиков \\ Тамбовский государственный университет имени Г.Р. Державина, \\ Россия, 392000, г. Тамбов, ул. Советская, 93 \\ E-mail: novikov9156765178@yandex.ru
}

\begin{abstract}
Аннотация. Важным этапом ортопедического лечения является изучение проблематики клинической картины и возможных последствий лечения. Потеря боковой группы зубов, несмотря на их относительную незначительность для эстетики, влияют на состояние жевательной функции. Однако часто включённые дефекты с потерей одного зуба недооцениваются пациентами, что приводит к большей протяжённости дефекта или к появлению концевого дефекта и, соответственно, к большему снижению жевательной функции. Сложность ортопедического лечения возрастает с протяжённостью дефектов. Проведено исследование проблемы ортопедического лечения пациентов с концевыми дефектами зубного ряда в зависимости от пола и срока вторичной адентии и влияния частичного съёмного протезирования на протезное ложе, функции зубочелюстной системы и опорные зубы. Исследование производилось при помощи частичных съёмных пластинчатых протезов с удерживающими кламмерами и базисом из полиметилметакрилата. Было установлено, что при увеличении срока адентии происходит снижение вероятности удачности лечения, увеличение выраженности осложнений на слизистой оболочке протезного ложа, а также более быстрый износ зубных протезов.
\end{abstract}

Ключевые слова: ортопедическое лечение, концевые дефекты зубных рядов, частичный съёмный зубной протез, протезное ложе, проблема лечения.

Для цитирования: Микляев С.В., Леонова О.М., Сальников А.Н., Новиков А.В. 2020. Проблема ортопедического лечения больных с концевыми дефектами зубного ряда. Актуальные проблемы медицины, 43 (3): 404-411. DOI: 10.18413/2687-0940-2020-43-3-404-411

\section{The problem of orthopaedic dental treatment in patients with free- end edentulous spaces}

\author{
Stanislav V. Miklyaev, Olga M. Leonova, Alexander N. Salnikov, Alexander V. Novikov \\ Derzhavin Tambov State University, \\ 93 Sovetskaya St., Tambov, 392000, Russia \\ E-mail: novikov9156765178@yandex.ru
}

\begin{abstract}
An important stage of orthopedic treatment is to study the problems of the clinical picture and possible consequences of treatment. The loss of the lateral group of teeth, despite their relative insignificance for aesthetics, affects the state of chewing function. However, often included defects with the loss of one tooth are underestimated by patients, which leads to a greater extent of the defect or to the appearance of a terminal defect and, consequently, to a greater decrease in chewing function. The complexity of orthopedic treatment increases with the length of defects. A study of the problem of
\end{abstract}


orthopedic treatment of patients with free-end edentulous spaces on the gender and duration of secondary adentia and the impact of partial removable denture on the denture-bearing area, the function of the dentition system and supporting teeth. The study was performed using partial removable plate dentures with retaining klammers and a base made of polymethylmethacrylate. It was found that with an increase in the period of adentia, there is a decrease in the probability of successful treatment, an increase in the severity of complications on the mucosa of the denture-bearing area as well as faster wear of dentures.

Keywords: orthopaedic dental treatment, free-end edentulous spaces, removable partial denture, denturebearing area, problem of treatment.

For citation: Miklyaev S.V., Leonova O.M., Salnikov A.N., Novikov A.V. 2020. The problem of orthopaedic dental treatment in patients with free- end edentulous spaces. Challenges in Modern Medicine, 43 (3): 404-411 (in Russian). DOI: 10.18413/2687-0940-2020-43-3-404-411

\section{Введение}

Одной из самых распространённых причин обращения пациентов за стоматологической ортопедической помощью является частичное отсутствие зубов. Причинами потери зубов наиболее часто являются неудовлетворительная гигиена, заболевания пародонта, сильно разрушенные зубы вследствие кариеса и его осложнений, травмы, вредные привычки. Во время исследований структуры заболеваемости данной патологией было выявлено, что концевые дефекты встречаются в $20 \%$ случаев [Кресникова и др., 2007]. При этом у 42,3 \% пациентов присутствуют двусторонние концевые дефекты и 44,8 \% пациентов имеют односторонние концевые дефекты [Тимошенко и др., 2013]. На нижней челюсти концевые дефекты определяются чаще, чем на верхней челюсти - 41,5 \% и 37,9 \% случаев соответственно [Мирзоева, 2014].

Концевые дефекты зубного ряда при потере только вторых моляров не имеют серьёзных последствий для зубочелюстной системы, как это бывает при включённых дефектах, и симптоматика достаточно бедна, однако всё же происходит ухудшение качества жевания, и при сохранившемся зубе-антагонисте происходит феномен Попова - Годона. При более протяжённых дефектах клиническая картина осложняется - вследствие потери первых моляров, которые являются «ключами» окклюзии и имеют большую жевательную функцию, происходит функциональная перегрузка и деформация зубного ряда в области фронтальной группы зубов, что приводит к последующей потере зубов [Жук и др., 2008]. Данные осложнения влекут за собой нарушение функции жевания и речи, повышенное стирание режущих поверхностей зубов, снижение межальвеолярной высоты [Hobkirk et al., 2003]. При отсутствии своевременного лечения происходят более глубокие осложнения, которые выражаются в функциональных и морфологических нарушениях работы жевательных мышц и височно-нижнечелюстного сустава [Лелари и др., 2017].

Приведённые выше осложнения возникают по причинам несвоевременного ортопедического лечения: финансовые затруднения, боязнь ортопедических процедур, эстетический дискомфорт, неудачное протезирование в прошлом, страх ношения протеза.

Ортопедическое лечение концевых дефектов представляет собой сложную задачу изза большой жевательной нагрузки, проблемы передачи её распределения, а также сложности фиксации съёмных протезов в этой области. Со временем эти причины приводят к проблеме концевого седла. Это осложнение возникает, когда базис съёмного протеза на дистальном участке погружается больше в слизистую оболочку десны, чем около опорного зуба, что в дальнейшем ведёт к атрофии альвеолярного отростка на этом участке.

Цель: изучить и оценить эффективность и осложнения ортопедического стоматологического лечения при концевых дефектах съёмными частичными протезами в зависимости от возраста, длительности существования дефекта у пациентов. 


\section{Материалы и методы исследования}

Клинические исследования основаны на результатах ортопедического лечения 60 пациентов в возрасте от 20 до 60 лет с дефектами зубных рядов I и II класса по Кеннеди. Для исследования отбирались пациенты только с концевыми дефектами зубного ряда, без патологической подвижности опорных зубов, пациенты, которые никогда не протезировались частичными съёмными протезами.

Критерии исключения больных из дальнейшего исследования:

1. У пациента имеется сахарный диабет I или II типа.

2. Наличие остеопороза и различных инфекционных заболеваний.

3. Проживание в районах техногенных катастроф.

4. Профессиональная деятельность связана с вредными для организма физическими, химическими факторами.

5. Наличие отягощенного аллергологического анамнеза.

6. Беременность.

7. Наличие новообразований.

8. Прием различных лекарственных препаратов, которые оказывают влияние на уровень костной резорбции и гипертрофию десен.

Ортопедическое лечение было произведено частичными съёмными пластинчатыми протезами с удерживающими кламмерами с базисами из полиметилметакрилата на стоматологической кафедре медицинского института ФГБОУ ВО «Тамбовского государственного университета им. Г.Р. Державина». Наблюдение проводилось на протяжении двух лет.

Все пациенты были разделены на 3 возрастные группы, в каждой группе было одинаковое количество мужчин и женщин. Первая группа состояла из пациентов возрастом от 20 до 35 лет, вторая - от 36 до 45 лет, третья группа - от 46 до 60 лет (см. таблицу).

Таблица

Table

Распределение пациентов по возрастным группам

Distribution of patients by age group

\begin{tabular}{|l|c|c|c|}
\hline \multicolumn{1}{|c|}{ Возрастная группа } & Мужчины & Женщины & Всего пациентов \\
\hline Группа № 1 & 5 & 5 & 10 \\
\hline Группа № 2 & 8 & 8 & 16 \\
\hline Группа № 3 & 17 & 17 & 34 \\
\hline Итого & 30 & 30 & 60 \\
\hline
\end{tabular}

В ходе проведения исследования были применены следующие методы:

- анализ медицинской документации;

- оценка состояния альвеолярного гребня и слизистой оболочки десны до и после протезирования;

- оценка качества прилегания частичного съёмного протеза к слизистой протезного ложа;

- оценка состояния зубного протеза в процессе эксплуатации.

\section{Результаты исследования и их обсуждение}

Перед протезированием с целью оценки состояния альвеолярного гребня и слизистой оболочки десны. В группе № 1 у 8 (80 \%) пациентов была лёгкая степень атрофии альвеолярного отростка, с сохранением нормальной щёчно-язычной ширины (по классификации J.S. Seibert (1983) II класс), слизистая оболочка слегка податливая без патологических изменений. У 2 (25 \%) пациентов в этой группе слизистая оболочка атрофированная, альвеолярный отросток умеренно выражен, с сохранением нормальной щёчно- 
язычной ширины. Протяжённость дефектов у пациентов не превышала в среднем 1-2 зуба. У 2 (20\%) пациентов отмечалось стирание режущих поверхностей зубов, превышающее возрастную, со снижением межальвеолярной высоты и дискомфорт в височнонижнечелюстном суставе при жевании и артикуляции.

После протезирования на протяжении 1 года были проведены профилактические осмотры. В 90 \% (9 пациентов) случаев пациенты не предъявляли жалоб, однако все пациенты испытывали дискомфорт при жевании, артикуляции, движениях челюсти, которые исчезали в течение 1-2 месяцев. У 1 (10\%) пациента дискомфорт при жевании исчез только к концу 1 года использования протеза.

При использовании съёмного частичного протеза около двух лет у пациентов отмечались следующие жалобы: ощущение боли при жевании в области протезного ложа $20 \%$ (2 пациента) (мужчины - 20\% (2 пациент)), подвижность и ухудшение фиксации протеза - 30 \% (женщины - 10 \% (1 пациент), мужчины - 20 \% (2 пациента); нижняя челюсть - $10 \%$ (1 пациент), верхняя челюсть - $20 \%$ (2 пациента)).

Обследование слизистой оболочки протезного ложа выявило, что у большинства пациентов отмечалась плотная слизистая оболочка бледно-розового цвета, иногда встречались очаги неравномерного красного цвета.

Снижение высоты альвеолярного отростка у пациентов была незначительная. Прогрессирование патологической стёртости окклюзионной поверхности зубов не происходило и дискомфорт в височно-нижнечелюстном суставе не выявлялся.

При исследовании состояния съёмных частичных протезов неудовлетворительное качество было выявлено в 20 \% случаев, при этом у мужчин дефекты протезов встречались чаще, чем у женщин. Дефекты протезов заключались в неравномерном истирании искусственных зубов, лёгкой степени деформации базиса протеза.

В группе № 2 у 8 (50\%) пациентов - в области концевых дефектов выраженная атрофия альвеолярных отростков, слизистая оболочка протезного ложа рыхлая, гипертрофированная, у 7 (43,75 \%) - слизистая оболочка атрофированная, альвеолярный отросток умеренно выражен. У 1 (6,25 \%) пациента - лёгкая степень атрофии альвеолярного отростка, слизистая оболочка слегка податливая, без патологических изменений. Во всех случаях был определён II класс дефекта по J.S. Seibert. Протяжённость дефектов у пациентов - в среднем 1-3 зуба. У 5 (31,25\%) пациентов отмечалась стёртость, превышающая возрастную, со снижением межальвеолярной высоты и боль в височно-нижнечелюстном суставе при жевании и артикуляции.

За 1 год профилактических осмотров протезированной области были получены следующие результаты: 5 (31,25 \%) пациентов испытывали дискомфорт при жевании и артикуляции, который проходил в течение 1-2 месяцев, у 25 \% (4 пациента) адаптация к протезу происходила к шестому месяцу использования, 31,25 \% (5 пациентов) адаптировались к протезу только к концу первого года, 2 (12,5 \%) пациента не смогли использовать протез по причине регулярного спадания при жевании.

Использование протеза в течение двух лет приводило к следующим жалобам: ощущение боли при жевании в области протезного ложа в $31,25 \%$ случаев (5 пациентов) (женщины - 12,5\% (2 пациента), мужчины - 18,75\% (3 пациента)), чувство жжения 37,5 \% (6 пациентов) (женщины - 18,75 \% (3 пациента), мужчины - 18,75 \% (3 пациента), подвижность и ухудшение фиксации протеза - 43,75 \% (7 пациентов) (женщины - 18,75 \% (3 пациента), мужчины - 25 \% (4 пациента); нижняя челюсть - 18,75 \% (3 пациента), верхняя челюсть $-25 \%$ (4 пациента)).

Обследование слизистой оболочки протезного ложа показало, что у 3 (18,75 \%) исследуемых пациентов отмечалась гиперемия, у остальных же пациентов воспалительных процессов на слизистой оболочке не отмечалось.

Заметное прогрессирование атрофии кости альвеолярного отростка наблюдалась только у 2 (12,5 \%) пациентов, которые не смогли использовать протезы. Болевые ощуще- 
ния в височно-нижнечелюстном суставе и повышенное стирание режущих поверхностей зубов сохранились также у пациентов, не использовавших зубные протезы. У больных с удачным протезированием отмечалось снижение или отсутствие боли в суставе.

Исследование состояния съёмных частичных протезов выявило неудовлетворительное качество у 43,75\% пациентов в данной группе (у мужчин дефекты протезов встречались чаще, чем у женщин). Дефекты протезов заключались в сильном неравномерном истирании искусственных зубов, умеренной деформации базиса, нарушении клапанных качеств протеза, повышении подвижности протеза.

В группе № 3 у 21 (61,76 \%) пациента - атрофия костной ткани выраженная, определена комбинированная вертикальная и горизонтальная потеря костной ткани (III класс по классификации J.S. Seibert), слизистая оболочка протезного ложа рыхлая, гипертрофированная. У 8 (23,52 \%) исследуемых пациентов альвеолярный отросток очень слабо выражен и также выявлен III класс, слизистая оболочка рыхлая. У 5 пациентов $(14,7 \%)-$ слизистая оболочка атрофированная, альвеолярный отросток умеренно выражен, II класс дефекта. Протяжённость дефектов у пациентов в среднем 2-3 зуба. У 17 (50 \%) пациентов отмечалась стёртость, превышающая возрастную, со снижением межальвеолярной высоты и выраженные боли в височно-нижнечелюстном суставе при жевании и артикуляции, выявлялось снижение слуха.

При проведении профилактических осмотров в течение 1 года после протезирования установлено, что у 17 (50 \%) пациентов адаптация к частичному съёмному протезу происходила к концу первого года использования. 10 (28,42 \%) пациентов не могли пользоваться протезом, так как при жевании и движениях челюсти происходило регулярное выпадение протеза. У 7 (21,58 \%) пациентов чувство дискомфорта проходило в течение первых 4-6 месяцев.

Осмотры протезного ложа за второй год использования протеза выявили, что частота случаев жалоб, полученных в двух других группах, увеличилась. Так, ощущение боли при жевании в области протезного ложа у 17 (50\%) пациентов (женщины - 26,47 \% (9 пациентов), мужчины - 23,52 \% (8 пациентов)), чувство жжения - 64,7 \% (22 пациента) (женщины - 35,29 \% (12 пациентов), мужчины - 29,41 \% (10 пациентов)), подвижность и ухудшение фиксации протеза - 58,82 \% (20 пациентов) (женщины - 26,47 \% (9 пациентов), мужчины - 32,35 \% (11 пациентов); нижняя челюсть - 26,47 \% (9 пациентов), верхняя челюсть - 32,35 \% (11 пациентов)). Также была выявлена проблема концевого седла, данное осложнение встретилось у 2 (5,88 \%) пациентов.

На слизистой оболочке десны в области протезного ложа выявлялась гиперемия у 30 \% исследуемых пациентов. У 5 \% пациентов отмечалась атрофия слизистой оболочки в дистальном отделе по причине проблемы концевого седла, у остальных пациентов патологии слизистой оболочки не наблюдалось.

Прогрессирование атрофии альвеолярной костной ткани наблюдалась у 12 (35,3\%) пациентов (28,42 \% - атрофия вследствие невозможности использования протеза, 5,88 \% проблема концевого седла). Выраженная боль в суставе и повышенная стёртость режущих поверхностей зубов сохранялись или прогрессировали у $10(28,42 \%)$ пациентов, которые не могли использовать протезы. У остальных пациентов боль в височно-нижнечелюстном суставе снижалась и не проявлялось снижение слуха.

Неудовлетворительное состояние протезов отмечалось у 21 (61,76 \%) пациента, причём чаще у мужчин, чем у женщин. Дефекты имели большую степень выраженности по сравнению с дефектами, выявленных в группе № 2.

В группах № 2 и № 3 были выявлены случаи невозможности использовать протез из-за регулярного спадания, причём встречаемость данного осложнения была выше на верхней челюсти, чем на нижней. При детальном осмотре полученных оттисков и базисов съёмных частичных протезов было выявлено неудовлетворительное отображение бугра верхней челюсти. Бугор верхней челюсти является обязательной точкой ретенции для съёмных протезов. Несмотря на высокую сложность снятия оттиска в этой области, боль- 
шое значение имеет атрофия альвеолярного отростка и, как следствие, происходит атрофия бугра верхней челюсти. При длительном отсутствии зубов после их потери происходит атрофия альвеолярного отростка, так как после удаления происходит выпадение этого участка кости из жевательной функции [Лебеденко и др., 2020].

Однако атрофия альвеолярного отростка происходит при правильно сделанном протезе и регулярном его использовании. По данным выше результатам была замечена лишь незначительная атрофия, так как период наблюдений продолжался два года. Но по данным других исследований при использовании съёмных протезов от 2 до 8 лет происходит неравномерная атрофия костной ткани альвеолярного отростка и атрофия слизистой оболочки протезного ложа [Галонский и др., 2009]. Причиной этих осложнений служит не физиологичная передача жевательного давления на протезное ложе, так как альвеолярная кость больше приспособлена к силам растяжения, исходящим от периодонта, чем к силам сжатия, которые исходят от базиса съёмного протеза [Щербаков и др., 1998].

На слизистой оболочке протезного ложа также в группах № 2 и № 3 были обнаружены воспалительные процессы, но протезного стоматита травматического происхождения не наблюдалось. Недостаточная гигиена полости рта и небольшая подвижность съёмного протеза в совокупности приводят к гиперемии слизистой оболочки. При этом воспалительные явления встречались чаще у мужчин, чем у женщин, что можно связать с меньшим качеством гигиены полости рта. Однако у женщин после 50 лет воспалительные явления встречаются чаще в связи с понижением защитно-барьерной функции эпителия, именно поэтому в группе № 3 частота воспалительных явлений повысилась у женщин [Галонский и др., 2009].

Дефекты протезов выявлялись во всех группах в разной степени выраженности. Самыми частыми дефектами были неравномерное истирание искусственных зубов, деформация базиса и кламмеров протеза и, как следствие, повышение подвижности протеза. Степень выраженности приведённых дефектов зависели не только от материала, из которого сделан протез (полиметилметакрилат не является самым прочным материалом для базиса), но и от степени атрофии альвеолярного гребня и пола пациента. Так, с увеличением атрофии альвеолярного отростка увеличивается нагрузка на базис протеза, что также приводит к деформации кламмеров и может со временем привести к патологической подвижности опорных зубов. Патологическая подвижность основана на неадекватной нагрузке на зуб, которая основана на эффекте рычага съёмного протеза, и чем больше протяжённость протеза, тем сильнее выражен эффект рычага, но снизить эффект можно с помощью многозвеньевых кламмеров. По результатам проведённого исследования патологической подвижности опорных зубов не наблюдалось, однако, по данным литературы, это осложнение наблюдается от $7 \%$ до 46,3\% пациентов. Также было замечено, что деформация базиса протеза происходила чаще у мужчин, чем у женщин - это может быть следствием развития большей жевательной нагрузки. Деформация базиса протеза вследствие перегрузки приводит к перелому базиса и кламмеров протеза. В зависимости от выраженности неблагоприятной клинической картины перелом базиса встречается у 9-21\% пациентов, перелом кламмеров у 7,5-15 \% пациентов [Жолудев, 2014; Трунин и др., 2018].

\section{Выводы}

Согласно проведенному нами исследованию, удачное ортопедическое лечение концевых дефектов зубного ряда зависит от клинической картины - самым значимым фактором является степень атрофии альвеолярного гребня. Чем протяжённее дефект и длительнее срок потери зубов, тем хуже выражена альвеолярная кость и меньше вероятность удачного лечения.

Однако удачность ортопедического лечения зависит не только от клинической картины, но и от метода протезирования. Несмотря на недостатки частичного съёмного про- 
тезирования, этот метод является стандартом ортопедической помощи. Конечно, частичные съёмные протезы не решают полностью проблему атрофии альвеолярной кости, но они являются самыми доступными по цене и относительно просты в изготовлении. А также устраняют основные осложнения, возникающие при концевых дефектах, по средствам восстановления жевательной функции, предупреждения и снижения дальнейшей деформации зубного ряда и функционально-морфологических изменений в височнонижнечелюстном суставе.

\section{Список литературы}

1. Галонский В.Г., Радкевич А.А. 2009. Реакция слизистой оболочки опорных тканей протезного ложа на воздействие съемных зубных протезов. Сибирский медицинский журнал, 2: 18-22.

2. Жолудев С.Е. 2014. Анализ ошибок и осложнений, допущенных при изготовлении съемных конструкций зубных рядов, по данным консультативного профессорского приема. Уральский медицинский журнал, 5 (119): 54-61.

3. Жук А.О., Лепилин А.В., Дмитриенко С.В. 2008. Оценка эффективности применения внутрикостных имплантатов при раннем удалении первых постоянных моляров. Материалы XI Всероссийской научно-практической конференции с международным участием «Новые технологии в стоматологии и имплантологии». Саратов, 156-157.

4. Кресникова Ю.В., Малый А.Ю., Бровко В.В. Ирошникова Е.С., Онуфриев А.Б. 2007. Клинико-эпидемиологический анализ результатов ортопедического лечения больных с частичным отсутствием зубов в регионах России. Проблемы стандартизации в здравоохранении, 6: 21-28.

5. Лебеденко И.Ю., Брагин Е.А., Рыжова И.П. 2020. Ортопедическая стоматология: 3-е изд., перераб. и доп. - М.: ГЭОТАР-Медиа, 330.

6. Лелари О.В., Поспелов А.Н. 2017. Сравнение частоты встречаемости дисфункции ВНЧС при односторонних и двусторонних концевых дефектах. Бюллетень медицинских интернет конференций, 1-7: 402-403.

7. Мирзоева П.Р. 2014. Частота и характер дефектов в зубных рядах как фактор, определяющий ортопедическую стоматологическую нуждаемость взрослого населения г. Баку. Современная стоматология, 3: 104-107.

8. Тимошенко А.Г., Брагин Е.А. 2013. Структура нуждаемости в ортопедической стоматологической помощи лиц, проживающих в ставропольском краевом геронтологическом центре. Кубанский научный медицинский вестник, 6 (141): 175-179.

9. Трунин Д.А., Садыков М.И., Нестеров А.М., Постников М.А., Нестеров Г.М., Чистякова М.С. 2018. Проблема ортопедического лечения больных с концевыми дефектами зубного ряда. Медицинский вестник Северного Кавказа, 13 (2): 441-446.

10. Щербаков А.С., Гаврилов Е.И., Трезубов В.Н., Жулев Е.Н. 1998. Ортопедическая стоматология. СПб. ИКФ «Фолиант»: 324.

11. John A. Hobkirk, Roger M. Watson, Lloyd J.J. Searson. 2003. Introducing Dental Implants. London, Churchill Livinstone, 115.

\section{References}

1. Galonsky V.G., Radkevich A.A. 2009. Reakcija slizistoj obolochki opornyh tkanej proteznogo lozha na vozdejstvie semnyh zubnyh protezov [The reaction of the mucous membrane of the supporting tissues of the prosthetic bed to the impact of removable dentures]. Sibirsky meditsinsky zhurnal, 2: 18-22.

2. Zholudev S.E. 2014. Analiz oshibok i oslozhnenij, dopushhennyh pri izgotovlenii s"emnyh konstrukcij zubnyh rjadov, po dannym konsul'tativnogo professorskogo priema [Analysis of errors and complications made during the manufacture of removable denture designs, according to the advisory professors reception]. Uralsky meditsinsky zhurnal, 5(119): 54-61.

3. Zhuk A.O., Lepilin A.V, Dmitrienko S.V. 2008. Ocenka jeffektivnosti primenenija vnutrikostnyh implantatov pri rannem udalenii pervyh postojannyh moljarov [Evaluating the effectiveness of intraosseous implants for early removal of the first permanent molars]. Materialy XI Vserossijskoj nauchno-prakticheskoj. konferencii s mezhdunarodnym uchastiem «Novye tehnologii v stomatologii $\mathrm{i}$ implantologii». Saratov, 156-157. 
4. Kresnikova Yu.V., Malyj A.Yu., Brovko V.V., Iroshnikova E.S., Onufriev A.B. 2007. Kliniko-jepidemiologicheskij analiz rezul'tatov ortopedicheskogo lechenija bol'nyh s chastichnym otsutstviem zubov v regionah Rossii [Clinical and epidemiologic study of prosthetic treatment for partial adentia in Russian regions]. Problemy standartizatsii v zdravookhranenii, (6): 21-28.

5. Lebedenko I.Yu., Bragin E.A., Ryzhova I.P. 2020. Ortopedicheskaja stomatologija [Orthopedic dentistry]: 3-e izd., pererab. i dop. - Moscow: GJeOTAR-Media, 330.

6. Lelari O.V., Pospelov A.N. 2017. Sravnenie chastoty vstrechaemosti disfunkcii VNChS pri odnostoronnih i dvustoronnih koncevyh defektah [Comparison of the incidence of TMJ dysfunction in unilateral and bilateral end defects]. Byulleten meditsinskikh internet konferentsy, 1-7: 402-403.

7. Mirzoyeva P.R. 2014. Chastota i harakter defektov $v$ zubnyh rjadah kak faktor, opredeljajushhij ortopedicheskuju stomatologicheskuju nuzhdaemost' vzroslogo naselenija g. Baku [Frequency and character of defects in dental lines as the factor determining orthopedic stomatologic needs of adult population of Baku]. Sovremennaya ortopedicheskaya stomatologiya, 3: 104-107.

8. Timoshenko A.G., Bragin E.A. 2013. Struktura nuzhdaemosti v ortopedicheskoj stomatologicheskoj pomoshhi lic, prozhivajushhih v Stavropol'skom kraevom gerontologicheskom centre [Structure tested in orthopedic dental care of persons living in the Stavropol regional gerontology centre]. Kubansky nauchny meditsinsky vestnik, 6 (141): 175-179.

9. Trunin D.A., Sadykov M.I., Nesterov A.M., Postnikov M.A., Nesterov G.M., Chistyakova M.S. 2018. Problema ortopedicheskogo lechenija bol'nyh s koncevymi defektami zubnogo rjada [The problem of orthopaedic dental treatment in patients with free-end edentulous spaces]. Medical News of North Caucasus, 13 (2): 441-446.

10. Shherbakov A.S., Gavrilov E.I., Trezubov V.N., Zhulev E.N. 1998. Ortopedicheskaja stomatologija [Orthopedic dentistry]. Saint Petersburg, IKF «Foliant», 324.

11. John A. Hobkirk, Roger M. Watson, Lloyd J.J. Searson. 2003. Introducing Dental Implants. London, Churchill Livinstone, 115.

\section{ИНФОРМАЦИЯ ОБ АВТОРАХ}

Микляев Станислав Валерьевич, кандидат медицинских наук, старший преподаватель кафедры стоматологии медицинского института Тамбовского государственного университета имени Г.Р. Державина, г. Тамбов, Россия

\begin{tabular}{lcr} 
Леонова Ольга & \multicolumn{1}{c}{ Михайловна, } & заведующая \\
кафедрой & стоматологии, & старший \\
преподаватель & кафедры & стоматологии \\
медицинского & института & Тамбовского \\
государственного & университета & имени \\
Г.Р. Державина, г. Тамбов, Россия &
\end{tabular}

Сальников Александр Николаевич, кандидат медицинских наук, доцент кафедры стоматологии медицинского института Тамбовского государственного университета имени Г.Р. Державина, г. Тамбов, Россия

Новиков Александр Викторович, студент медицинского института Тамбовского государственного университета имени Г.Р. Державина, г. Тамбов, Россия

\section{INFORMATION ABOUT THE AUTHORS}

Stanislav V. Miklyaev, candidate of medical Sciences, chief lecturer of Dentistry Department of Medical Institute of Derzhavin Tambov State University, Tambov, Russia

Olga M. Leonova, head of Dentistry Department of Medical Institute of Derzhavin Tambov State University, head doctor of Tambov Regional Clinical Dental Care, Tambov, Russia

Alexander N. Salnikov, candidate of medical Sciences, docent of Dentistry Department of Medical Institute of Derzhavin Tambov State University, Tambov, Russia

Alexander V. Novikov, student of Dentistry Department of Medical Institute of Derzhavin Tambov State University, Tambov, Russia 